\title{
The Role of Glucagon in Glycemic Variability in Type I Diabetes: A Narrative Review
}

\section{Keyu Guo* \\ Qi Tian $\mathbb{1}^{*}$ \\ Lin Yang \\ Zhiguang Zhou}

National Clinical Research Center for Metabolic Diseases, Key Laboratory of Diabetes Immunology, Ministry of Education, and Department of Metabolism and Endocrinology, The Second Xiangya Hospital of Central South University, Changsha, 4I00II, Hunan, People's Republic of China

*These authors contributed equally to this work
Correspondence: Lin Yang; Zhiguang

Zhou

Email yanglin_nfm@csu.edu.cn;

zhouzhiguang@csu.edu.cn

\begin{abstract}
Type 1 diabetes mellitus (T1DM) is a progressive disease as a result of the severe destruction of islet $\beta$-cell function, which leads to high glucose variability in patients. However, $\alpha$-cell function is also compromised in patients with T1DM, characterized by aberrant fasting and postprandial glucagon secretion. According to recent studies, this aberrant glucagon secretion plays an increasing role in hyperglycemia, insulin-induced hypoglycemia and exercise-associated hypoglycemia in patients with T1DM. With application of continuous glucose monitoring system, dozens of metrics enable the assessment of glycemic variability, which is an integral component of glycemic control for patients with T1DM. There is growing evidences to illustrate the contribution of glucagon secretion to the glycemic variability in patients with T1DM, which may promote the development of new treatment strategies aiming to mitigate glycemic variability associated with aberrant glucagon secretion.
\end{abstract}

Keywords: type 1 diabetes, glucagon secretion, continuous glucose monitoring, hyperglycemia, hypoglycemia, glycemic variability

\section{Key Summary Points}

Why carry out this study?

Aberrant glucagon secretion also contributes to T1DM.

The contribution of glucagon secretion to glycemic variability in patients with T1DM has not been clarified.

What is learned from the study?

In addition to $\beta$-cell dysfunction, aberrant glucagon secretion also contributes to glycemic variability in type 1 diabetes.

Glucagon suppression or inactivation may underlie potential therapeutic advantages over insulin monotherapy.

\section{Introduction}

Type 1 diabetes mellitus (T1DM) is a chronic, immune-mediated disease on account of the destruction of islet $\beta$-cell that leads to insulin deficiency. ${ }^{1-3}$ Multiple genetic and environmental factors are involved in the development of $\beta$ cell-targeted autoimmune processes and $\beta$-cell dysfunction. ${ }^{4}$ However, $\alpha$-cell function and gene expression are also compromised in T1DM. ${ }^{5}$ Dysfunction of $\alpha$-cell can aggravate hyperglycemia caused by abnormally elevated glucagon and hypoglycemia resulting from insufficient glucagon due to failure of counter regulation, ${ }^{6}$ such as impaired glucagon secretion making patients with T1DM more prone to 
insulin-induced hypoglycemia and postprandial hyperglycemia associated with hyperglucagonemia. ${ }^{7,8}$

Glucagon is a proglucagon-derived peptide hormone secreted from pancreatic islet $\alpha$-cell in response to hypoglycemia, ${ }^{9}$ as well as has a reaction to nutrients, hormones, neurotransmitters, and drugs. ${ }^{10,11}$ Glucagon, as a glucose-regulating hormone, can counteract excessive insulin action and play an important role in maintaining blood glucose homeostasis. ${ }^{10-12}$ In healthy individuals, physiological glucagon levels are in the range of 20-40 $\mathrm{pg} / \mathrm{mL}$ in fasting state, which is twice as much as that in prandial state. ${ }^{6,13,14}$ In contrast, individuals with T1DM are characterized by postprandial hyperglucagonemia and inadequate glucagon secretion during hypoglycemia. The bi-hormonal hypothesis of diabetes was first proposed by Roger Unger, ${ }^{15}$ arguing that diabetes is as much caused by glucagon excess as insulin deficiency, and its association with T1DM has been known for nearly half a century. ${ }^{16,17}$ In recent years, studies surrounding the glucagon receptor in rodents with T1DM have demonstrated that glucagon plays an important part in regulating glucose homeostasis, ${ }^{18-21}$ which gives support to clinical observations discussed in the following.

Glycemic variability (GV) is an integral component of glycemic control in patients with T1DM, ${ }^{22,23}$ which can represent the presence of excess glycemic excursions and, consequently, the risk of hyperglycemia or hypoglycemia. ${ }^{24,25} \mathrm{With}$ application of continuous glucose monitoring system (CGMs) since the late 1990s, dozens of metrics enable estimation of GV in patients with T1DM. ${ }^{26-28}$ Some studies showed that $\mathrm{GV}$ was associated with diabetic complications in T1DM, ${ }^{29-32}$ but this remained controversial ${ }^{33-38}$ and needed to be elucidated by further prospective studies on a large group of diabetes patients using CGM. Besides, it was reported that GV influenced the quality of life in patients with T1DM. ${ }^{39-41}$ Recent studies proposed GV in T1DM is not only due to the insulin deficiency, but also due in part to the aberrant dynamics of glucagon secretion.

Papers published up to December 2020 in the PubMed database were reviewed using the terms "glucagon", "type 1 diabetes", "hypoglycemia", "hyperglycemia" and "glycemic variability". The references of pertinent articles were also handsearched for relevant papers. Only papers published in English were considered.

\section{Glucagon Secretion in TIDM}

It is generally acknowledged that the aberrant glucagon secretion dramatically affects glucose control in patients with T1DM, ${ }^{6,42}$ even at the special stage, the partial remission (PR) phase generally called "the honeymoon", which is characterized by transient $\beta$-cell function recovery and better glycemic control accompanied by lower insulin requirement. ${ }^{43}$ PR after diagnosis of T1DM were more prone to have lower glucagon secretion than nonremission. ${ }^{44}$ The aberrant glucagon secretion in fasting and postprandial state is a complex phenomenon that plays a pivotal role in aggregating hyperglycemia and hypoglycemia in patients with T1DM.

\section{Fasting Glucagon Secretion in TIDM}

By comparison of serial sampling data, it was found that there was significant elevation of fasting glucagon in patients with $\mathrm{T} 1 \mathrm{DM},{ }^{45}$ which was in line with the results of non-insulin treatment type 2 diabetes mellitus $(\mathrm{T} 2 \mathrm{DM})^{46}$ and T1DM with different disease durations. ${ }^{47}$ However, other researchers found that fasting glucagon concentrations in new onset T1DM remained within the health control reference range over 12 months. ${ }^{48,49}$ There are multiple interpretations for these incompletely consistent results, such as differences in subjects, insulin resistance and detection methods, ${ }^{50-53}$ but certainly not all. The inhibition of glucagon secretion by insulin is the core mechanisms involved in the regulation of glucagon secretion. ${ }^{54,55}$ It's understandable, then, that elevated fasting glucagon is associated with disease durations in T1DM, which is conditional on rates of decrease in $\beta$ cell function. ${ }^{56}$ Besides, earlier study in T1DM patients without residual $\beta$-cell function clearly demonstrated that exogenous insulin can restrain responses to other glucagon secretagogues. ${ }^{57}$ As expected, exogenous insulin infusion was shown to suppress glucagon secretion. ${ }^{58,59}$ Based on these data, it can be observed that exogenous insulin does not fully normalize glucagon secretion in poorly controlled T1DM patients. On the contrary, in insulin-treated and relatively well-controlled T1DM patients, fasting glucagon levels tend to be within normal range, suggesting that hyperglucagonemia may not be detected if only sampling in fasting state.

\section{Postprandial Glucagon Secretion in TIDM}

The postprandial hyperglucagonemia plays a role in initiation and maintenance of postprandial hyperglycemia in T1DM even including LADA (latent autoimmune diabetes in adults) and T2DM. ${ }^{60-62}$ The early study showed 
postprandial plasma glucagon level increased $160 \%$ in five years follow-up period after diagnosis of T1DM, which was negatively associated with postprandial C-peptide, an index to evaluate the residual $\beta$-cell function. ${ }^{63}$ Further study also showed that residual $\beta$-cell function had potential impact on postprandial glucagon in some individuals with long-standing T1DM. ${ }^{64}$ Recent study in T1DM with more than 3 years duration suggested that patients with high postprandial glucose tended to have high postprandial plasma glucagon, ${ }^{65}$ which may exacerbate glycemic control gradually. Therefore, it is clear that the trend of gradual aggravation in postprandial hyperglucagonemia in line with the progressive reduction in $\beta$-cell function. Intriguingly, the aberrant increase in postprandial glucagon showed no inversion when euglycemia was achieved prior to oral glucose test in patients with $\mathrm{T} 1 \mathrm{DM},{ }^{66}$ which demonstrated the postprandial hyperglucagonemia in T1DM irrespective of ambient glycemia. Besides, the secretion of glucagon is inhibited during hyperglycemia by paracrine mechanisms of insulin, zinc, and GABA secreted by $\beta$-cell. ${ }^{67-69}$ When the postprandial glucose level increases, $\beta$-cell is stimulated simultaneously. As alteration of $\beta$-cell function, individuals with T1DM have no power to completely inhibit glucagon secretion. ${ }^{70,71}$ It might result in the postprandial hyperglucagonemia, which is consistent with the U-shaped dose-response curve for glucose-regulated glucagon secretion obtained in animal experiment. ${ }^{72}$ These findings illustrate that postprandial hyperglycemia induces glucagon secretion, which in turn exacerbates postprandial hyperglucagonemia. Of course, it triggers a vicious circle.

\section{Glucagon Secretion and Hyperglycemia in TIDM}

Previous studies have clearly shown that aberrant hypersecretion of glucagon plays a key role in inducing hyperglycemia in patients with T1DM. $^{73}$ The early study ${ }^{74}$ reported postprandial glucagon increased by $17 \%$ and C-peptide decreased by half from baseline levels in the first year after diagnosis. Further studies on C-peptidenegative T1DM patients suggested that plasma glucagon concentration might be higher in hyperglycemic patients, ${ }^{65,75}$ which was consistent with the study between total pancreatectomy and T1DM with a complete lack of endogenous insulin. ${ }^{76}$ There is some evidence that the impact of glucagon response on early postprandial glucose excursion is independent of residual $\beta$-cell function in type
1 diabetes. ${ }^{77}$ In summary, there is growing evidences that, aberrant hyperglucagonemia, under the condition of relative insulin deficiency, is one of the main pathogenesis of hyperglycemia in patients with T1DM.

Another interesting phenomenon was that patients with T1DM manifested hyperglucagonemia when suffering from diabetic ketoacidosis, ${ }^{16}$ which contributed not only to their pronounced hyperglycemia but also to their hyperketonemia. Glucagon increases hepatic glucose and ketone production, in the case of insulin deficiency. ${ }^{73}$ The somatostatin, the first glucagon-suppressing agent, ${ }^{78}$ reduced plasma $\beta$-hydroxybutyrate and glucose level in patients after temporary withdrawal of insulin with T1DM. ${ }^{79}$ Because these T1DM patients almost certainly lost considerable $\beta$-cell function, it was rational to attribute the hypoglycemic effect of somatostatin to its inhibition of glucagon secretion. ${ }^{54}$ Besides, administration of somatostatin analog also allowed some patients to achieve better glycemic control ${ }^{80}$ and the suppression of glucagon secretion might increase insulin sensitivity at the same time. $^{81,82}$

\section{Glucagon Secretion and Hypoglycemia in TIDM}

The risk of hypoglycemia in individuals with T1DM is high: about $12 \%$ of the patients experience severe hypoglycemia with loss of consciousness per year. ${ }^{83}$ Insulininduced hypoglycemia is customarily the result of the interaction between excessive exogenous insulin and aberrant glucagon secretion in T1DM. This kind of hypoglycemia is main complication of T1DM and is estimated to account for $4 \%$ of all-cause mortality in patients with T1DM. ${ }^{84}$ The early study suggested that the glucagon response to hypoglycemia was lost as early as the first month after diagnosis of $\mathrm{T} 1 \mathrm{DM},{ }^{85}$ which was consistent with the finding that aberrant glucagon secretion during hypoglycemia was commonly observed after the first year, in youth with T1DM. ${ }^{86}$ The glucagon response to hypoglycemia in patients with T1DM is relevant to the duration of diabetes and can be deprived early in the disease. The physiological mechanism for the speedy deprivation of the glucagon response to hypoglycemia is certainly multifactorial. Most important of these is likely the decrease of insulin secretion and the aberrant counter-regulation of glucagon secretion during hypoglycemia. However, this counter regulation follows the recognition of hypoglycemia by the autonomic nervous system. Early studies 
suggested that marked loss of islet sympathetic nerves as well as diabetic autonomic neuropathy could destroy the recognition function of hypoglycemia in patients with T1DM. $^{87,88}$ Intriguingly, a recent study in adults with T1DM reported that impaired awareness of hypoglycemia was not associated with autonomic dysfunction or peripheral neuropathy. ${ }^{89}$ For these reasons, the aberrant glucagon secretion is one of the key components in pathophysiology of insulin-induced hypoglycemia, although the exact mechanisms in vivo remain to be identified.

Exercise is a fundamental component of diabetes management. Current guidelines recommend that individuals with T1DM can benefit from physical activity, and exercise should be recommended to all. ${ }^{90}$ However, the complexity of exercise-associated management has become a major impediment to attainment of regular exercise at recommended levels for many patients with T1DM. Although both mean peak glucagon levels and the AUC (area under the curve) glucagon had little difference between individuals with T1DM and health controls during exercise, ${ }^{91}$ the episodes of hypoglycemia would influence glucagon secretion. Therefore, the addition of glucagon might have great potential to reduce hypoglycemia during exercise. Low-dose glucagon was more effective in preventing exercise-induced hypoglycemia than the reduction of insulin dosage and might result in less postintervention hyperglycemia than carbohydrate supplement. $^{92}$ The artificial pancreas, combining storage and delivery of insulin and glucagon with $\mathrm{CGM}^{93}$ is a highly effective and safe approach for treating T1DM. $^{94,95}$ The dual-hormone artificial pancreas has a better practicality in glycemic control during exercise than the single-hormone artificial pancreas in patients with T1DM. $^{96}$

\section{Glucagon Secretion and Glycemic Variability in TIDM}

$\mathrm{GV}$ is an integral component of glycemic control in patients with T1DM, closely associated with insulin deficiency as well as aberrant glucagon secretion during glycemic changes, such as a deficient glucagon response to hypoglycemia and a relative hyperglucagonemia during hyperglycemia. These aberrant glucagon secretions might be related to $\mathrm{GV}$ in patients with T1DM, which is a serious clinical problem and a major consideration when evaluating quality of glycemic control. GV increases progressively from prediabetes to advanced
T2DM and is much higher in T1DM. ${ }^{97,98}$ Besides, the increased availability of CGM offers dozens of metrics for variability and enables measurement and observation of GV within a day and intraday, a more rigorous and valuable approach to evaluate glycemic control in daily life. ${ }^{98}$ Therefore, to illustrate the contribution of glucagon secretion to $\mathrm{GV}$ in patients with T1DM may promote the development of new treatment strategies, could eventually mitigate $\mathrm{GV}$ associated with aberrant glucagon secretion. $^{99}$

\section{Glucagon Secretion and Glycemic Variability Calculated by CGM}

In a study exploring the relationship between aberrant glucagon secretion and GV in T1DM with different disease duration, ${ }^{47}$ the correlation between fasting glucagon levels and SD (standard deviation of glucose) and MAGE (mean amplitude of glycemic excursions) was demonstrated. As mentioned above, in insulin-treated and relatively well-controlled T1DM patients, fasting glucagon levels are prone to be within normal range. Fasting glucagon may reflect the status of glycemic control and is potentially used as an index to predict GV. Further study showed positive correlations between some parameters of $\mathrm{GV}$ and arginine-stimulated postprandial glucagon secretion response in T1DM without any endogenous insulin. ${ }^{75}$ In this study, patients with higher AUC glucagon tended to have higher SD and MAGE. In addition, recent research also showed positive associations between measurement of GV and AUC glucagon undergoing arginine stimulation tests and AUC glucagon was significantly correlated with the SD. ${ }^{100}$ Moreover, other measurements of GV such as MODD (absolute means of daily differences) and LBGI (low blood glucose index) were also reported to be significantly correlated with AUC glucagon in T1DM. ${ }^{47}$ So far, from the above researches it can be seen that fasting glucagon, postprandial glucagon and AUC of glucagon are all closely related to GV. Furthermore, it was reported that metrics of $\mathrm{GV}$ were predictors of aberrant glucagon secretion. CV (coefficient of variation) and CONGA (continuous overall net glycemic action) were correlated with change in glucagon concentration during the progressive fall in plasma glucose and might be predictors of impaired glucagon responses to insulin-induced hypoglycemia in patients with T1DM. ${ }^{101}$

According to the above research findings in patients with T1DM, dysfunction of $\beta$-cell responsiveness to 
hyperglycemia as well as $\alpha$-cell responsiveness to hypoglycemia likely resulted in higher GV demonstrated by CGM, and the contribution of aberrant glucagon secretion was indeed not negligible.

\section{Glucagon Suppression or Inactivation and Glucose Variability Migration}

The aforementioned findings suggest that glucagon suppression or inactivation may underlie potential therapeutic advantages over insulin monotherapy. ${ }^{102}$ The adjunctive treatment of GLP-1 analogue liraglutide to insulin therapy was effective in well-controlled T1DM characterized by reduction in glycemic excursions and insulin dose. ${ }^{103}$ Besides, the addition of pramlintide created a more efficient capacity to suppress the postprandial glucagon secretion than liraglutide. ${ }^{104}$ Similarly, compared with baseline and control patients, there was a significant decrease of arginine-stimulated glucagon secretion with a concomitant reduction of the MAGE and $\mathrm{CV}$ in exenatide-treated patients, although it had no effect on glucagon during hypoglycemia. ${ }^{105}$ However, the DPP-4 inhibitor vildagliptin combined with insulin in T1DM retained glucagon counter-regulation during hypoglycemia while improved glycemic excursion due to, at least in part, the inhibition on postprandial glucagon secretion. ${ }^{106}$ Another study has also shown reduction in AUC glucagon and changes in $\mathrm{GV}$ and insulin requirement in the linagliptin group, although not statistically significant, after all it was a small size study. ${ }^{107}$ Moreover, the addition of glucagon might also have great potential to improve glycemic control. For example, the improved mean glycemia and reduced hypoglycemia with the dual-hormone artificial pancreas relative to insulin pump therapy in preadolescent children was reported in T1DM. ${ }^{92}$ Besides, patients with T1DM displayed absolute glucagon concentrations and a decrease in glucagon levels across the night comparable to those observed in the healthy control subjects. ${ }^{108}$ The application of dual-hormone artificial pancreas systems also provided better overnight glucose control than conventional therapy with T1DM. ${ }^{109}$

\section{Discussion}

Glucagon is a critical regulator of glucose homeostasis ${ }^{110}$ and the aberrant glucagon secretion in patients with T1DM is heterogeneous that is not fixed over the course of disease and poor glycemic control would flow from these changes, even in patients with tight glycemic control. ${ }^{6,42}$ The effect of aberrant glucagon secretion includes hyperglycemia owing to paradoxical increase in glucagon, postprandial hyperglucagonemia in particular, and hypoglycemia induced by inadequate glucagon secretion. Emerging therapies designed to improve aberrant glucagon secretion are promising to mitigate $\mathrm{GV}$.

The challenge, of course, is to interpret the available research results of glucagon concentration in patients with T1DM on account of the use of different assays. ${ }^{6}$ RIA kits use polyclonal antibodies against the glucagon $\mathrm{C}$-terminal region, which will cross-react with proglucagon, truncated forms of glucagon and other fragments also containing this C-terminal region. ${ }^{14}$ Subsequently, with the advent of double-sandwich ELISA kits, these monoclonal antibodies against both the $\mathrm{C}$ - and $\mathrm{N}$-terminal regions of glucagon allow for greater accuracy and have power to detect small changes with little cross-reactivity to other fragments. Therefore, the aberrant glucagon secretion in patients with T1DM needs to be revised based on previous results obtained from RIA kits. ${ }^{13} \mathrm{Next}$, one of multiple possible reasons for discrepant results between studies on glucagon secretion is probably due to the stimuli of various amino acid composition in the different tests, such as MMTT, oral glucose, arginine stimulation, etc. Thus, there is an urgent need to establish the method of standardization of glucagon assay, and it is important to select the methods to stimulate and detect glucagon scientifically and rationally.

What's more, T1DM is a progressive disease, and a more in-depth research of aberrant glucagon secretion at different stages of T1DM has been hindered by the incapable of early diagnosis before overt decline of insulin secretion and hyperglycemia. Therefore, prospective multicenter studies with large sample size are needed in different stages, especially prediabetes and first-degree relatives of T1DM, to confirm the present findings.

\section{Compliance with Ethics Guideline}

This article is based on previously conducted studies and does not contain any new studies with human participants or animals performed by any of the authors.

\section{Acknowledgments}

The authors would like to thank the department of metabolism and endocrinology of the Second Xiangya Hospital of Central South University. 


\section{Author Contributions}

All authors made a significant contribution to the work reported, whether that is in the conception, study design, execution, acquisition of data, analysis and interpretation, or in all these areas; took part in drafting, revising or critically reviewing the article; gave final approval of the version to be published; have agreed on the journal to which the article has been submitted; and agree to be accountable for all aspects of the work.

\section{Funding}

This work was supported by the National Key R\&D Program of China (Grant No. 2018YFC2001005).

\section{Disclosure}

Dr Keyu Guo, Dr Qi Tian, Prof. Dr. Lin Yang, and Prof. Dr Zhiguang Zhou report grants from government, during the conduct of the study. Keyu Guo, Qi Tian, Lin Yang, and Zhiguang Zhou declare that the research was conducted in the absence of any commercial or financial relationships that could be construed as a potential conflict of interest.

\section{References}

1. Norris JM, Johnson RK, Stene LC. Type 1 diabetes-early life origins and changing epidemiology. Lancet Diabetes Endocrinol. 2020;8(3):226-238. doi:10.1016/S2213-8587(19) 30412-7

2. Yang L, Luo S, Huang G, et al. The diagnostic value of zinc transporter 8 autoantibody (ZnT8A) for type 1 diabetes in Chinese. Diabetes Metab Res Rev. 2010;26(7):579-584. doi:10.1002/dmrr.1128

3. Huang J, Xiao Y, Xu A, Zhou Z. Neutrophils in type 1 diabetes. $J$ Diabetes Investig. 2016;7(5):652-663. doi:10.1111/jdi.12469

4. Ilonen J, Lempainen J, Veijola R. The heterogeneous pathogenesis of type 1 diabetes mellitus. Nat Rev Endocrinol. 2019;15 (11):635-650. doi:10.1038/s41574-019-0254-y

5. Brissova M, Haliyur R, Saunders D, et al. Alpha cell function and gene expression are compromised in type 1 diabetes. Cell Rep. 2018;22(10):2667-2676. doi:10.1016/j.celrep.2018.02.032

6. Campbell JE, Drucker DJ. Islet alpha cells and glucagon-critical regulators of energy homeostasis. Nat Rev Endocrinol. 2015;11 (6):329-338. doi:10.1038/nrendo.2015.51

7. Bolli G, De Feo P, Perriello G, et al. Mechanisms of glucagon secretion during insulin-induced hypoglycemia in man. Role of the beta cell and arterial hyperinsulinemia. J Clin Invest. 1984;73 (4):917-922. doi:10.1172/JCI111315

8. Schwandt P. [Insulin-induced hypoglycemia]. Dtsch Med Wochenschr. 1983;108(20):802-803. German.

9. Cryer PE. Mechanisms of hypoglycemia-associated autonomic failure in diabetes. $N$ Engl $J$ Med. 2013;369(4):362-372. doi:10.1056/NEJMra1215228

10. Marks V. Glucagon. Clin Endocrinol Metab. 1972;1(3):829-845. doi:10.1016/S0300-595X(72)80045-8
11. Briant L, Salehi A, Vergari E, Zhang Q, Rorsman P. Glucagon secretion from pancreatic alpha-cells. Ups J Med Sci. 2016;121 (2):113-119. doi:10.3109/03009734.2016.1156789

12. Cryer PE. Glycemic goals in diabetes: trade-off between glycemic control and iatrogenic hypoglycemia. Diabetes. 2014;63 (7):2188-2195. doi:10.2337/db14-0059

13. Wewer Albrechtsen NJ, Hartmann B, Veedfald S, et al. Hyperglucagonaemia analysed by glucagon sandwich ELISA: nonspecific interference or truly elevated levels? Diabetologia. 2014;57(9):1919-1926. doi:10.1007/s00125-014-3283-z

14. Bak MJ, Albrechtsen NW, Pedersen J, et al. Specificity and sensitivity of commercially available assays for glucagon and oxyntomodulin measurement in humans. Eur $J$ Endocrinol. 2014;170(4):529-538. doi:10.1530/EJE-13-0941

15. Unger RH, Parris EE, Unger RH. Glucagon physiology and pathophysiology. $N$ Engl $J$ Med. 1971;285(8):443-449. doi:10.1056/NEJM197108192850806

16. Muller WA, Faloona GR, Unger RH. Hyperglucagonemia in diabetic ketoacidosis. Its prevalence and significance. $\mathrm{Am}$ J Med. 1973;54(1):52-57. doi:10.1016/0002-9343(73)90083-1

17. Gerich JE, Langlois M, Noacco C, Karam JH, Forsham PH. Lack of glucagon response to hypoglycemia in diabetes: evidence for an intrinsic pancreatic alpha cell defect. Science. 1973;182 (4108):171-173. doi:10.1126/science.182.4108.171

18. Lee Y, Wang MY, Du XQ, Charron MJ, Unger RH. Glucagon receptor knockout prevents insulin-deficient type 1 diabetes in mice. Diabetes. 2011;60(2):391-397. doi:10.2337/db10-0426

19. Wang MY, Yan H, Shi Z, et al. Glucagon receptor antibody completely suppresses type 1 diabetes phenotype without insulin by disrupting a novel diabetogenic pathway. Proc Natl Acad Sci $U$ S $S$ A. 2015;112(8):2503-2508. doi:10.1073/ pnas. 1424934112

20. Jun LS, Millican RL, Hawkins ED, et al. Absence of glucagon and insulin action reveals a role for the GLP-1 receptor in endogenous glucose production. Diabetes. 2015;64(3):819-827. doi: $10.2337 / \mathrm{db} 14-1052$

21. Damond N, Thorel F, Moyers JS, et al. Blockade of glucagon signaling prevents or reverses diabetes onset only if residual beta-cells persist. Elife. 2016;5. doi:10.7554/eLife.13828

22. Battelino T, Danne T, Bergenstal RM, et al. Clinical targets for continuous glucose monitoring data interpretation: recommendations from the international consensus on time in range. Diabetes Care. 2019;42(8):1593-1603. doi:10.2337/dci19-0028

23. Danne T, Nimri R, Battelino T, et al. International consensus on use of continuous glucose monitoring. Diabetes Care. 2017;40 (12):1631-1640. doi:10.2337/dc17-1600

24. Ceriello A, Monnier L, Owens D. Glycaemic variability in diabetes: clinical and therapeutic implications. Lancet Diabetes Endocrinol. 2019;7(3):221-230. doi:10.1016/S2213-8587(18) 30136-0

25. Rama Chandran S, Tay WL, Lye WK, et al. Beyond HbAlc: comparing glycemic variability and glycemic indices in predicting hypoglycemia in Type 1 and Type 2 diabetes. Diabetes Technol Ther. 2018;20(5):353-362. doi:10.1089/dia.2017.0388

26. Rodbard D. Glucose variability: a review of clinical applications and research developments. Diabetes Technol Ther. 2018;20(S2): S25-s215. doi:10.1089/dia.2018.0092

27. Rama Chandran S, Jacob P, Choudhary P. Baseline glucose variability and inter-week variability affects time to stability of continuous glucose monitoring (CGM) derived indices. Diabetes Technol Ther. 2020;22:937-942. doi:10.1089/dia.2020.0011

28. Zheng F, Jalbert M, Forbes F, et al. Characterization of daily glycemic variability in subjects with type 1 diabetes using a mixture of metrics. Diabetes Technol Ther. 2020;22 (4):301-313. doi:10.1089/dia.2019.0250 
29. Picconi F, Parravano M, Ylli D, et al. Retinal neurodegeneration in patients with type 1 diabetes mellitus: the role of glycemic variability. Acta Diabetol. 2017;54(5):489-497. doi:10.1007/ s00592-017-0971-4

30. Šoupal J, Škrha J, Fajmon M, et al. Glycemic variability is higher in type 1 diabetes patients with microvascular complications irrespective of glycemic control. Diabetes Technol Ther. 2014;16(4):198-203. doi:10.1089/dia.2013.0205

31. Jun JE, Lee SE, Lee YB, et al. Continuous glucose monitoring defined glucose variability is associated with cardiovascular autonomic neuropathy in type 1 diabetes. Diabetes Metab Res Rev. 2019;35(2):e3092. doi:10.1002/dmrr.3092

32. Snell-Bergeon JK, Roman R, Rodbard D, et al. Glycaemic variability is associated with coronary artery calcium in men with type 1 diabetes: the coronary artery calcification in type 1 diabetes study. Diabet Med. 2010;27:1436-1442. doi:10.1111/j.14645491.2010.03127.x

33. Siegelaar SE, Kilpatrick ES, Rigby AS, et al. Glucose variability does not contribute to the development of peripheral and autonomic neuropathy in type 1 diabetes: data from the DCCT. Diabetologia. 2009;52(10):2229-2232. doi:10.1007/s00125-0091473-x

34. Kilpatrick ES, Rigby AS, Atkin SL. Effect of glucose variability on the long-term risk of microvascular complications in type 1 diabetes. Diabetes Care. 2009;32(10):1901-1903. doi:10.2337/ dc09-0109

35. Kilpatrick ES, Rigby AS, Atkin SL. The effect of glucose variability on the risk of microvascular complications in type 1 diabetes. Diabetes Care. 2006;29(7):1486-1490. doi:10.2337/ dc06-0293

36. Lachin JM, Bebu I, Bergenstal RM, et al. Association of glycemic variability in type 1 diabetes With progression of microvascular outcomes in the diabetes control and complications trial. Diabetes Care. 2017;40(6):777-783. doi:10.2337/dc16-2426

37. Sartore G, Chilelli NC, Burlina S, et al. Association between glucose variability as assessed by continuous glucose monitoring (CGM) and diabetic retinopathy in type 1 and type 2 diabetes. Acta Diabetol. 2013;50(3):437-442. doi:10.1007/s00592-0130459-9

38. Smith-Palmer J, Brändle M, Trevisan R, et al. Assessment of the association between glycemic variability and diabetes-related complications in type 1 and type 2 diabetes. Diabetes Res Clin Pract. 2014;105(3):273-284. doi:10.1016/j.diabres.2014.06.007

39. Polonsky WH, Hessler D, Ruedy KJ, Beck RW. The impact of continuous glucose monitoring on markers of quality of life in adults with type 1 diabetes: further findings from the DIAMOND randomized clinical trial. Diabetes Care. 2017;40(6):736-741. doi:10.2337/dc17-0133

40. Ayano-Takahara S, Ikeda K, Fujimoto S, et al. Glycemic variability is associated with quality of life and treatment satisfaction in patients with type 1 diabetes. Diabetes Care. 2015;38(1):e1e2. doi:10.2337/dc14-1801

41. Reddy M, Godsland IF, Barnard KD, et al. Glycemic variability and its impact on quality of life in adults with type 1 diabetes. $J$ Diabetes Sci Technol. 2015;10(1):60-66. doi:10.1177/ 1932296815601440

42. Yosten GLC. Alpha cell dysfunction in type 1 diabetes. Peptides. 2018;100:54-60. doi:10.1016/j.peptides.2017.12.001

43. Li X, Zhong T, Tang R, et al. PD-1 and PD-L1 expression in peripheral $\mathrm{CD} 4 / \mathrm{CD} 8+\mathrm{T}$ cells is restored in the partial remission phase in type 1 diabetes. $J$ Clin Endocrinol Metab. 2020;105:1947-1956. doi:10.1210/clinem/dgaa130

44. Scholin A, Nystrom L, Arnqvist H, et al. Proinsulin/C-peptide ratio, glucagon and remission in new-onset Type 1 diabetes mellitus in young adults. Diabet Med. 2011;28(2):156-161. doi:10.1111/j.1464-5491.2010.03191.x
45. Raskin P, Unger RH. Effect of insulin therapy on the profiles of plasma immunoreactive glucagon in juvenile-type and adult-type diabetics. Diabetes. 1978;27(4):411-419. doi:10.2337/ diab.27.4.411

46. Faerch K, Vistisen D, Pacini G, et al. Insulin resistance is accompanied by increased fasting glucagon and delayed glucagon suppression in individuals with normal and impaired glucose regulation. Diabetes. 2016;65(11):3473-3481. doi:10.2337/db160240

47. Li K, Song WJ, Wu X, et al. Associations of serum glucagon levels with glycemic variability in type 1 diabetes with different disease durations. Endocrine. 2018;61(3):473-481. doi:10.1007/ s12020-018-1641-1

48. Brown RJ, Sinaii N, Rother KI. Too much glucagon, too little insulin: time course of pancreatic islet dysfunction in new-onset type 1 diabetes. Diabetes Care. 2008;31(7):1403-1404. doi:10.2337/dc080575

49. Cooperberg BA, Cryer PE. Beta-cell-mediated signaling predominates over direct alpha-cell signaling in the regulation of glucagon secretion in humans. Diabetes Care. 2009;32 (12):2275-2280. doi:10.2337/dc09-0798

50. Ferrannini E, Muscelli E, Natali A, et al. Association of fasting glucagon and proinsulin concentrations with insulin resistance. Diabetologia. 2007;50(11):2342-2347. doi:10.1007/s00125-0070806-X

51. Geary N. Postprandial suppression of glucagon secretion: a puzzlement. Diabetes. 2017;66(5):1123-1125. doi:10.2337/ dbi16-0075

52. Kramer CK, Zinman B, Choi H, Connelly PW, Retnakaran R. The impact of chronic liraglutide therapy on glucagon secretion in type 2 diabetes: insight from the LIBRA trial. J Clin Endocrinol Metab. 2015;100(10):3702-3709. doi:10.1210/jc.2015-2725

53. Kramer CK, Zinman B, Choi H, Connelly PW, Retnakaran R. Impact of the glucagon assay when assessing the effect of chronic liraglutide therapy on glucagon secretion. J Clin Endocrinol Metab. 2017;102(8):2729-2733. doi:10.1210/jc.2017-00928

54. Cryer PE. Minireview: glucagon in the pathogenesis of hypoglycemia and hyperglycemia in diabetes. Endocrinology. 2012;153 (3):1039-1048. doi:10.1210/en.2011-1499

55. Cooperberg BA, Cryer PE. Insulin reciprocally regulates glucagon secretion in humans. Diabetes. 2010;59(11):2936-2940. doi: $10.2337 / \mathrm{db} 10-0728$

56. Adams JD, Dalla Man C, Laurenti MC, et al. Fasting glucagon concentrations are associated with longitudinal decline of beta-cell function in non-diabetic humans. Metabolism. 2020;105:154175. doi:10.1016/j.metabol.2020.154175

57. Asplin CM, Paquette TL, Palmer JP. In vivo inhibition of glucagon secretion by paracrine beta cell activity in man. J Clin Invest. 1981;68(1):314-318. doi:10.1172/JCI110251

58. Raskin P, Fujita Y, Unger RH. Effect of insulin-glucose infusions on plasma glucagon levels in fasting diabetics and nondiabetics. $J$ Clin Invest. 1975;56(5):1132-1138. doi:10.1172/JCI108188

59. Liu DT, Adamson UC, Lins PE, Kollind ME, Moberg EA, Andreasson K. Inhibitory effect of circulating insulin on glucagon secretion during hypoglycemia in type I diabetic patients. Diabetes Care. 1992;15(1):59-65. doi:10.2337/ diacare.15.1.59

60. Jiang $\mathrm{G}$, Zhang BB. Glucagon and regulation of glucose metabolism. Am J Physiol Endocrinol Metab. 2003;284(4): E671-E678. doi:10.1152/ajpendo.00492.2002

61. Wewer albrechtsen NJ, Kuhre RE, Pedersen J, Knop FK, Holst JJ. The biology of glucagon and the consequences of hyperglucagonemia. Biomark Med. 2016;10(11):1141-1151. doi:10.2217/bmm-2016-0090 
62. Carlsson A, Sundkvist G, Groop L, Tuomi T. Insulin and glucagon secretion in patients with slowly progressing autoimmune diabetes (LADA). J Clin Endocrinol Metab. 2000;85(1):76-80. doi:10.1210/jcem.85.1.6228

63. Fredheim S, Andersen ML, Porksen S, et al. The influence of glucagon on postprandial hyperglycaemia in children 5 years after onset of type 1 diabetes. Diabetologia. 2015;58(4):828-834. doi:10.1007/s00125-014-3486-3

64. Thivolet C, Marchand L, Chikh K. Inappropriate glucagon and GLP-1 secretion in individuals with long-standing type 1 diabetes: effects of residual C-peptide. Diabetologia. 2019;62 (4):593-597. doi:10.1007/s00125-018-4804-y

65. Urakami T, Nagano N, Suzuki J, Yoshida A, Takahashi S, Mugishima H. Influence of plasma glucagon levels on glycemic control in children with type 1 diabetes. Pediatr Int. 2011;53 (1):46-49. doi:10.1111/j.1442-200X.2010.03184.x

66. Kramer CK, Borgono CA, Van Nostrand P, Retnakaran R, Zinman B. Glucagon response to oral glucose challenge in type 1 diabetes: lack of impact of euglycemia. Diabetes Care. 2014;37 (4):1076-1082. doi:10.2337/dc13-2339

67. Greenbaum CJ, Havel PJ, Taborsky GJ, Klaff LJ. Intra-islet insulin permits glucose to directly suppress pancreatic A cell function. J Clin Invest. 1991;88(3):767-773. doi:10.1172/JCI115375

68. Wendt A, Birnir B, Buschard K, et al. Glucose inhibition of glucagon secretion from rat alpha-cells is mediated by GABA released from neighboring beta-cells. Diabetes. 2004;53 (4):1038-1045. doi:10.2337/diabetes.53.4.1038

69. Zhou H, Zhang T, Harmon JS, Bryan J, Robertson RP. Zinc, not insulin, regulates the rat alpha-cell response to hypoglycemia in vivo. Diabetes. 2007;56(4):1107-1112. doi:10.2337/db06-1454

70. Gylfe E, Gilon P. Glucose regulation of glucagon secretion. Diabetes Res Clin Pract. 2014;103(1):1-10. doi:10.1016/j. diabres.2013.11.019

71. Zhou H, Tran PO, Yang S, et al. Regulation of alpha-cell function by the beta-cell during hypoglycemia in Wistar rats: the "switchoff' hypothesis. Diabetes. 2004;53(6):1482-1487. doi:10.2337/ diabetes.53.6.1482

72. Salehi A, Vieira E, Gylfe E. Paradoxical stimulation of glucagon secretion by high glucose concentrations. Diabetes. 2006;55 (8):2318-2323. doi:10.2337/db06-0080

73. Unger RH, Cherrington AD. Glucagonocentric restructuring of diabetes: a pathophysiologic and therapeutic makeover. J Clin Invest. 2012;122(1):4-12. doi:10.1172/JCI60016

74. Porksen S, Nielsen LB, Kaas A, et al. Meal-stimulated glucagon release is associated with postprandial blood glucose level and does not interfere with glycemic control in children and adolescents with new-onset type 1 diabetes. J Clin Endocrinol Metab. 2007;92(8):2910-2916. doi:10.1210/jc.2007-0244

75. Bessho M, Murase-Mishiba Y, Tsutsumi C, et al. Glycaemic instability correlates with a hyperglucagonaemic response in patients with type 1 diabetes without residual beta-cell function. Diabetes Res Clin Pract. 2013;102(2):e38-E40. doi:10.1016/j. diabres.2013.09.003

76. Niwano F, Hiromine Y, Noso S, et al. Insulin deficiency with and without glucagon: a comparative study between total pancreatectomy and type 1 diabetes. $J$ Diabetes Investig. 2018;9 (5):1084-1090. doi:10.1111/jdi.12799

77. Ito A, Horie I, Miwa M, et al. Impact of glucagon response on early postprandial glucose excursions irrespective of residual $\beta$ cell function in type 1 diabetes: a cross-sectional study using a mixed meal tolerance test. $J$ Diabetes Investig. 2020;11:232-240. doi:10.1111/jdi.13096

78. Rivier J, Brazeau P, Vale W, et al. [Solid-phase total synthesis of a tetradecapeptide having the chemical and biological properties of somatostatine]. C R Acad Hebd Seances Acad Sci D. 1973;276 (19):2737-2740. French.
79. Gerich JE, Lorenzi M, Bier DM, et al. Prevention of human diabetic ketoacidosis by somatostatin. Evidence for an essential role of glucagon. $N$ Engl $J$ Med. 1975;292(19):985-989. doi:10.1056/NEJM197505082921901

80. Dimitriadis G, Gerich J. Effect of twice daily subcutaneous administration of a long-acting somatostatin analog on 24-hour plasma glucose profiles in patients with insulin-dependent diabetes mellitus. Horm Metab Res. 1985;17(10):510-511. doi:10.1055/s-2007-1013591

81. Orskov L, Moller N, Bak JF, Porksen N, Schmitz O. Effects of the somatostatin analog, octreotide, on glucose metabolism and insulin sensitivity in insulin-dependent diabetes mellitus. Metabolism. 1996;45(2):211-217. doi:10.1016/S0026-0495(96)90056-6

82. Bruttomesso D, Fongher C, Silvestri B, et al. Combination of continuous subcutaneous infusion of insulin and octreotide in Type 1 diabetic patients. Diabetes Res Clin Pract. 2001;51 (2):97-105. doi:10.1016/S0168-8227(00)00210-2

83. Weinstock RS, Xing D, Maahs DM, et al. Severe hypoglycemia and diabetic ketoacidosis in adults with type 1 diabetes: results from the T1D Exchange clinic registry. J Clin Endocrinol Metab. 2013;98(8):3411-3419. doi:10.1210/jc.2013-1589

84. Cryer PE. Hypoglycaemia: the limiting factor in the glycaemic management of type I and type II diabetes. Diabetologia. 2002;45 (7):937-948. doi:10.1007/s00125-002-0822-9

85. Siafarikas A, Johnston RJ, Bulsara MK, O’Leary P, Jones TW, Davis EA. Early loss of the glucagon response to hypoglycemia in adolescents with type 1 diabetes. Diabetes Care. 2012;35 (8):1757-1762. doi:10.2337/dc11-2010

86. Sherr J, Xing D, Ruedy KJ, et al. Lack of association between residual insulin production and glucagon response to hypoglycemia in youth with short duration of type 1 diabetes. Diabetes Care. 2013;36(6):1470-1476. doi:10.2337/dc12-1697

87. Mundinger TO, Mei Q, Foulis AK, Fligner CL, Hull RL, Taborsky GJ. Human type 1 diabetes is characterized by an early, marked, sustained, and Islet-selective loss of sympathetic nerves. Diabetes. 2016;65(8):2322-2330. doi:10.2337/db16-0284

88. Horie H, Hanafusa T, Matsuyama T, et al. Decreased response of epinephrine and norepinephrine to insulin-induced hypoglycemia in diabetic autonomic neuropathy. Horm Metab Res. 1984;16 (8):398-401. doi:10.1055/s-2007-1014802

89. Olsen SE, Bjorgaas MR, Asvold BO, et al. Impaired awareness of hypoglycemia in adults with type 1 diabetes is not associated with autonomic dysfunction or peripheral neuropathy. Diabetes Care. 2016;39(3):426-433. doi:10.2337/dc15-1469

90. Colberg SR, Sigal RJ, Yardley JE, et al. Physical activity/exercise and diabetes: a position statement of the American Diabetes Association. Diabetes Care. 2016;39(11):2065-2079. doi: $10.2337 / \mathrm{dc} 16-1728$

91. Adolfsson P, Nilsson S, Albertsson-Wikland K, Lindblad B. Hormonal response during physical exercise of different intensities in adolescents with type 1 diabetes and healthy controls. Pediatr Diabetes. 2012;13(8):587-596. doi:10.1111/j.13995448.2012.00889.x

92. Rickels MR, DuBose SN, Toschi E, et al. Mini-dose glucagon as a novel approach to prevent exercise-induced hypoglycemia in type 1 diabetes. Diabetes Care. 2018;41(9):1909-1916. doi: $10.2337 / \mathrm{dc} 18-0051$

93. Doyle FJ, Huyett LM, Lee JB, Zisser HC, Dassau E. Closed-loop artificial pancreas systems: engineering the algorithms. Diabetes Care. 2014;37(5):1191-1197. doi:10.2337/dc13-2108

94. Weisman A, Bai JW, Cardinez M, Kramer CK, Perkins BA. Effect of artificial pancreas systems on glycaemic control in patients with type 1 diabetes: a systematic review and meta-analysis of outpatient randomised controlled trials. Lancet Diabetes Endocrinol. 2017;5(7):501-512. doi:10.1016/S22138587(17)30167-5 
95. Russell SJ, El-Khatib FH, Sinha M, et al. Outpatient glycemic control with a bionic pancreas in type 1 diabetes. $N$ Engl J Med 2014;371(4):313-325. doi:10.1056/NEJMoa1314474

96. Taleb N, Emami A, Suppere C, et al. Efficacy of single-hormone and dual-hormone artificial pancreas during continuous and interval exercise in adult patients with type 1 diabetes: randomised controlled crossover trial. Diabetologia. 2016;59(12):2561-2571. doi:10.1007/s00125-016-4107-0

97. Lu J, Ma X, Zhang L, et al. Glycemic variability modifies the relationship between time in range and hemoglobin A1c estimated from continuous glucose monitoring: a preliminary study. Diabetes Res Clin Pract. 2020;161:108032. doi:10.1016/j. diabres.2020.108032

98. Wilmot EG, Choudhary P, Leelarathna L, Baxter M. Glycaemic variability: the under-recognized therapeutic target in type 1 diabetes care. Diabetes Obes Metab. 2019;21(12):2599-2608. doi:10.1111/dom.13842

99. Hirsch IB, Brownlee M. Should minimal blood glucose variability become the gold standard of glycemic control? J Diabetes Complications. 2005;19(3):178-181. doi:10.1016/j.jdiacomp. 2004.10.001

100. Takahashi N, Chujo D, Kajio H, Ueki K. Contribution of pancreatic alpha-cell function to insulin sensitivity and glycemic variability in patients with type 1 diabetes. J Diabetes Investig. 2019;10(3):690-698. doi:10.1111/jdi.12949

101. Alghothani N, Dungan KM. The effect of glycemic variability on counterregulatory hormone responses to hypoglycemia in young children and adolescents with type 1 diabetes. Diabetes Technol Ther. 2011;13(11):1085-1089. doi:10.1089/dia.2011.0026

102. Shirin A, Della Rossa F, Klickstein I, Russell J, Sorrentino F, Singh A. Optimal regulation of blood glucose level in Type I diabetes using insulin and glucagon. PLoS One. 2019;14(3) e0213665. doi:10.1371/journal.pone.0213665
103. Varanasi A, Bellini N, Rawal D, et al. Liraglutide as additional treatment for type 1 diabetes. Eur J Endocrinol. 2011;165 (1):77-84. doi:10.1530/EJE-11-0330

104. Galderisi A, Sherr J, VanName M, et al. Pramlintide but not liraglutide suppresses meal-stimulated glucagon responses in type 1 diabetes. $J$ Clin Endocrinol Metab. 2018;103 (3):1088-1094. doi:10.1210/jc.2017-02265

105. Jiang LL, Wang SQ, Ding B, et al. The effects of add-on exenatide to insulin on glycemic variability and hypoglycemia in patients with type 1 diabetes mellitus. $J$ Endocrinol Invest. 2018;41(5):539-547. doi:10.1007/s40618-017-0765-0

106. Farngren J, Persson M, Schweizer A, Foley JE, Ahren B. Vildagliptin reduces glucagon during hyperglycemia and sustains glucagon counterregulation during hypoglycemia in type 1 diabetes. J Clin Endocrinol Metab. 2012;97(10):3799-3806. doi: $10.1210 /$ jc.2012-2332

107. Mukherjee S, Bhadada SK, Sachdeva N, et al. Effect of linagliptin on incretin-axis and glycaemic variability in T1DM. J Assoc Physicians India. 2018;66(7):28-32.

108. Jauch-Chara K, Hallschmid M, Schmid SM, et al. Plasma glucagon decreases during night-time sleep in type 1 diabetic patients and healthy control subjects. Diabet Med. 2007;24(6):684-687. doi:10.1111/j.1464-5491.2007.02116.x

109. Haidar A, Rabasa-Lhoret R, Legault L, et al. Single- and dual-hormone artificial pancreas for overnight glucose control in type 1 diabetes. J Clin Endocrinol Metab. 2016;101(1):214-223. doi:10.1210/jc.2015-3003

110. Kulina GR, Rayfield EJ. The role of glucagon in the pathophysiology and management of diabetes. Endocr Pract. 2016;22 (5):612-621. doi:10.4158/EP15984.RA

Diabetes, Metabolic Syndrome and Obesity: Targets and Therapy

Dovepress

\section{Publish your work in this journal}

Diabetes, Metabolic Syndrome and Obesity: Targets and Therapy is an international, peer-reviewed open-access journal committed to the rapid publication of the latest laboratory and clinical findings in the fields of diabetes, metabolic syndrome and obesity research. Original research, review, case reports, hypothesis formation, expert opinion and commentaries are all considered for publication. The manuscript management system is completely online and includes a very quick and fair peer-review system, which is all easy to use. Visit http://www.dovepress.com/testimonials.php to read real quotes from published authors.

Submit your manuscript here: https://www.dovepress.com/diabetes-metabolic-syndrome-and-obesity-targets-and-therapy-journal 